\title{
Balling Gun Delivery Device
}

National Cancer Institute

\section{Source}

National Cancer Institute. Balling Gun Delivery Device. NCI Thesaurus. Code C149349.

Device for delivery of a solid dose into the throat of the animal. 